\title{
Aprovechamiento escolar en aritmética: Objeto de aprendizaje en lengua de señas mexicana para sordos
}

\author{
Scholastic Achievement in Arithmetic: Learning Object in Mexican Sign Language \\ for Deafness People
}

Realização escolar em aritmética: objeto de aprendizagem da língua gestual mexicana para surdos

Juan José Rodríguez Peña Universidad Autónoma de Querétaro, México jrodriguez130@alumnos.uaq.mx https://orcid.org/0000-0001-8076-2037

Graciela Gerarda Ayala Jiménez Universidad Autónoma de Querétaro, México chelaaj@hotmail.com http://orcid.org/0000-0002-1889-1804

Manuel López Torrijo Universitat de València, España manuel.lopez-torrijo@uv.es https://orcid.org/0000-0002-0105-7194 


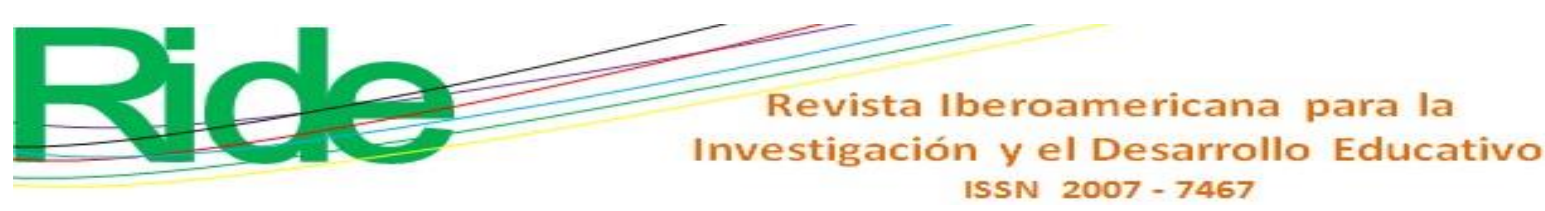

\section{Resumen}

El objetivo de este trabajo fue obtener evidencia de que se logra y favorece el aprovechamiento escolar, en específico en el área de la aritmética, con el empleo de un objeto de aprendizaje digital en estudiantes sordos que se comunican mediante la lengua de señas mexicana. Esto a través de una investigación de tipo cuantitativo experimental que consideró una muestra de 30 estudiantes de tercer grado de primaria en el municipio de Querétaro, México, quienes se distribuyeron en dos grupos: de control y experimental.

El instrumento y los datos obtenidos se validaron mediante la prueba estadística parametrizada $t$-Student: el resultado fue de $95 \%$ de intervalo de confianza. Además, se midió la confiabilidad de la prueba previa y la prueba posterior con el coeficiente de correlación de Pearson, y el aprovechamiento escolar se comprobó con el indicador estadístico de la ganancia normalizada de Hake. De esta manera, se concluyó que se favorece el aprovechamiento escolar con el uso de tecnología educativa. Se determinó que en el grupo experimental se observó una mejoría moderada en las operaciones de adición, sustracción, multiplicación y división de la aritmética, en comparación con las reportadas en el grupo de control. Finalmente, se recomienda la participación activa de las personas con déficit auditivo en la educación.

Palabras clave: aprendizaje en línea, aritmética, educación de sordos, experimento educacional, investigación pedagógica, programa informático didáctico.

\section{Abstract}

The objective of this work was to obtain evidence that school achievement is favored, specifically in the area of arithmetic, with the use of a digital learning object in deaf students who communicate through the Mexican sign language. This through an experimental quantitative research that considered a sample of 30 third grade students in the municipality of Querétaro, Mexico, who were divided into two groups: control and experimental.

The instrument and the data obtained were validated using the t-test: the result was $95 \%$ confidence interval. In addition, the reliability of the previous test and the subsequent test was measured with the Pearson correlation coefficient, and school achievement was checked with the statistical indicator of Hake's normalized gain. In this way, it was concluded that school achievement is favored with the use of educational technology. It was also determined that in the experimental group a moderate improvement was observed in the arithmetic operations of addition, 


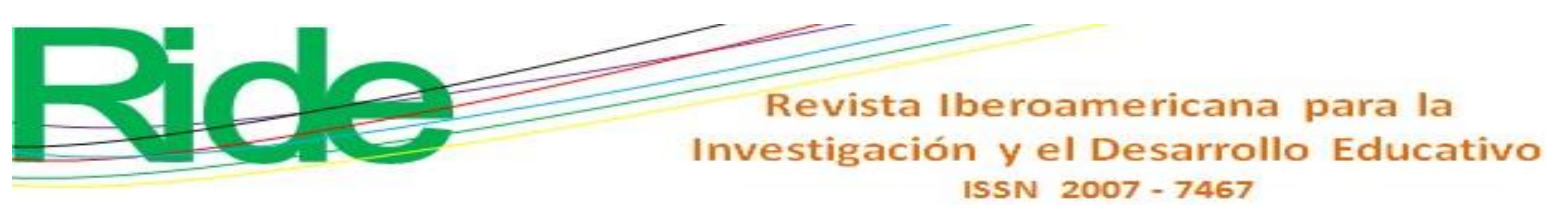

subtraction, multiplication, and division, compared to those reported in the control group. Finally, the active participation of people with hearing impairment in education is recommended.

Keywords: e-learning, arithmetic, education of the deaf, experimental education, pedagogical research, educational software.

\section{Resumo}

O objetivo deste trabalho foi obter evidências de que o desempenho escolar é alcançado e favorecido, especificamente na área da aritmética, com o uso de um objeto de aprendizado digital em estudantes surdos que se comunicam através da linguagem gestual mexicana. Isso por meio de uma pesquisa quantitativa experimental, que considerou uma amostra de 30 alunos da terceira série do município de Querétaro, México, divididos em dois grupos: controle e experimental.

$\mathrm{O}$ instrumento e os dados obtidos foram validados por meio do teste estatístico parametrizado tStudent: o resultado foi um intervalo de confiança de $95 \%$. Além disso, a confiabilidade do teste anterior e do teste subsequente com o coeficiente de correlação de Pearson foi mensurada, e o desempenho escolar foi verificado com o indicador estatístico do ganho normalizado de Hake. Dessa forma, concluiu-se que o desempenho escolar é favorecido com o uso da tecnologia educacional. Foi determinado que no grupo experimental foi observada melhora moderada nas operações de adição, subtração, multiplicação e divisão da aritmética, em comparação com as relatadas no grupo controle. Por fim, recomenda-se a participação ativa de pessoas com deficiência auditiva na educação.

Palavras-chave: aprendizagem on-line, aritmética, educação de surdos, experimento educacional, pesquisa pedagógica, programa didático de computador.

Fecha Recepción: Junio 2019

Fecha Aceptación: Noviembre 2019 


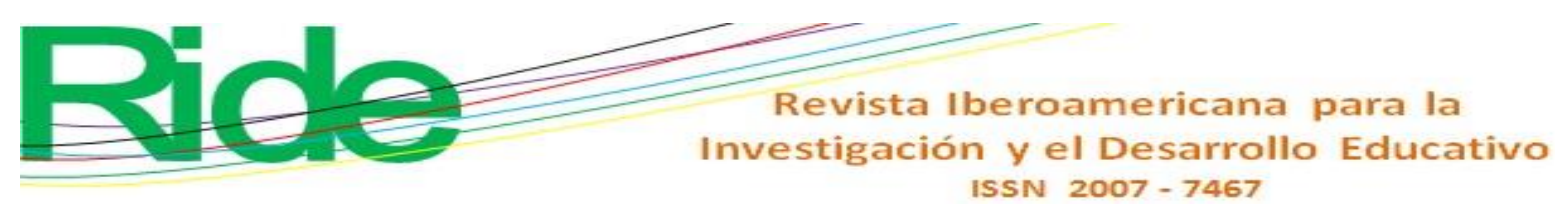

\section{Introducción}

Esta investigación propone que el aprovechamiento escolar esperado en el área de la aritmética en personas sordas se alcance a través de una intervención de pedagogía digital que favorezca la construcción de conceptos matemáticos y el conjunto de operaciones procedimentales. "En todo proceso de enseñanza, aun cuando se tengan aprendizajes esperados para todos los alumnos por igual, se debe tomar en cuenta que la manera de llegar a estos puede ser diferente para distintos alumnos" (Secretaría de Educación Pública [SEP], 2018, p. 13).

Es por ello por lo que los espacios, las estrategias, los materiales y las tecnologías aplicadas a la educación tienen que considerarse para atender la diversidad de necesidades educativas específicas de los estudiantes: mediante el aprovechamiento de los nuevos entornos de aprendizaje, que hoy están presentes en los procesos de enseñanza, gracias al uso de las tecnologías de la información y la comunicación (TIC). Los nuevos medios de comunicación como los teléfonos móviles, las tabletas y los equipos de cómputo facilitan el uso y su aplicación en los espacios de aprendizaje basados en el denominado personal learning environment (PLE), en los espacios web colaborativos, las redes sociales, aquellos fundamentados en juegos y en los llamados massive open online courses (MOOC) (Díaz, Baena y Baena, 2018, pp. 1-19). Claro está que la importancia de los docentes, los especialistas, el personal de apoyo y los familiares de las personas con déficit auditivo es igualmente trascendental, ya que son los que implementan estas mejoras y son los facilitadores de llevar a cabo estas prácticas educativas.

Para lograr esto:

Debe definirse la temática o asignatura, establecer quiénes serán los docentes colaboradores, el tipo de contenidos que se utilizarán, cómo se integrarán los módulos y las lecciones, cuáles serán los espacios de comunicación y la forma en que se fomentará la participación de los alumnos, la plataforma que será utilizada y los mecanismos de difusión del curso (Escudero y Nuñez, 2019, p. 135).

La Organización Mundial de la Salud [OMS] (2011) refiere en su resumen del Informe Mundial sobre la Discapacidad lo siguiente: "Las pruebas presentadas en este Informe señalan que muchos de los obstáculos a que se enfrentan las personas con discapacidad son evitables, y que pueden superarse las desventajas asociadas a la discapacidad" (p.18).

Al respecto, las personas sordas integran uno de los grupos vulnerables en la sociedad, y al igual que el resto requieren de la educación para mejorar su calidad de vida. Por lo que se consideró el entorno del sistema educativo mexicano y la normatividad vigente, referente a la Ley General 


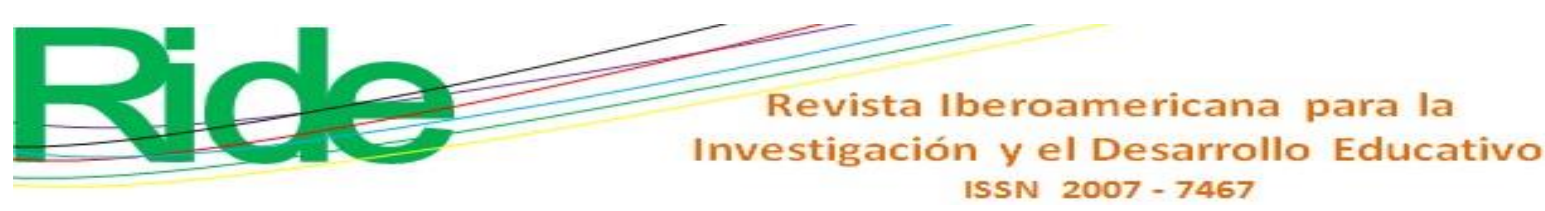

de Educación, a la Ley de Ciencia y Tecnología y especialmente a la Ley General para la Inclusión de las Personas con Discapacidad, que, en su última reforma publicada en 2018, en su capítulo III dedicado a la educación, artículo 12 fracción VI, dice lo puesto a continuación:

Proporcionar a los estudiantes con discapacidad; materiales y ayudas técnicas que apoyen su rendimiento académico, procurando equipar los planteles y centros educativos con libros de braille, materiales didácticos, apoyos de intérpretes de lengua de señas mexicana o especialistas en sistema braille, equipos computarizados con tecnología para personas ciegas y todos aquellos apoyos que se identifiquen como necesarios para brindar una educación con calidad (Cámara de Diputados, 2018, p. 10).

En los albores de este trabajo se identificó que una de las líneas de investigación de la tecnología educativa se encarga de estudiar que el uso de tecnología mejora el aprendizaje mediante los objetos de aprendizaje digitales, tal y como se muestra en la figura 1.

Figura 1. Contexto de la investigación cuantitativa experimental

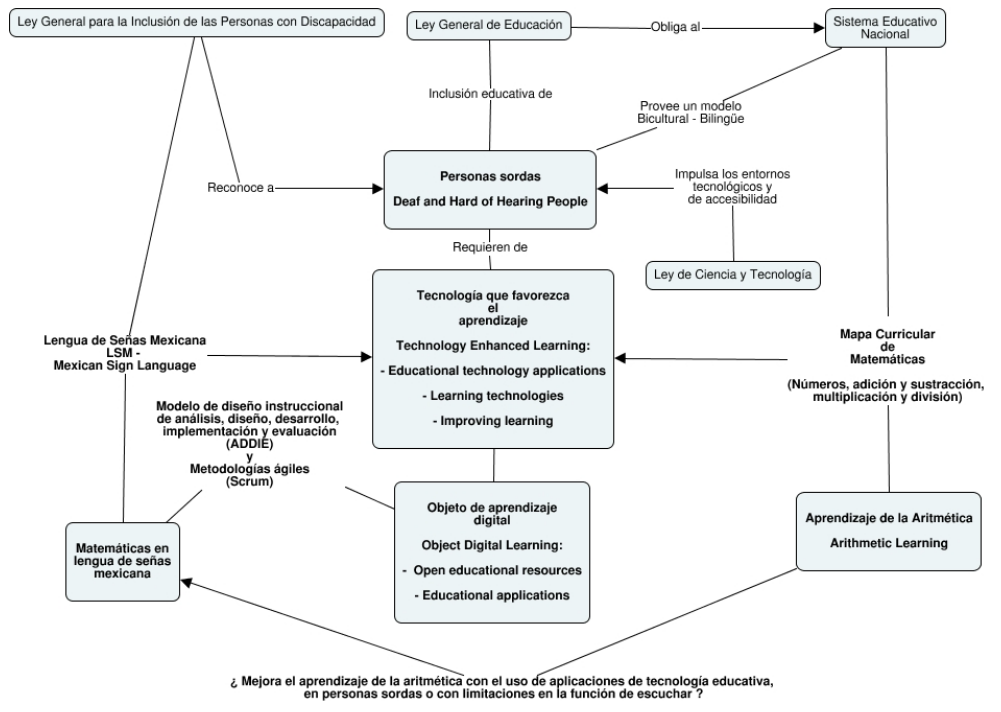

Fuente: Elaboración propia.

Así, pues, el aprovechamiento del estudiante sordo en la asignatura de las matemáticas, y en particular en la aritmética, área que estudia los números y las operaciones hechas con ellos, sirve como antecedente para iniciar con esta investigación.

Como parte también de los preliminares, se analizó el mapa curricular y la dosificación de conocimientos en matemáticas para los tres primeros años de primaria en los libros del maestro de la SEP (2018). Y se consultó el Diccionario de lenguaje mexicano de señas, particularmente la 


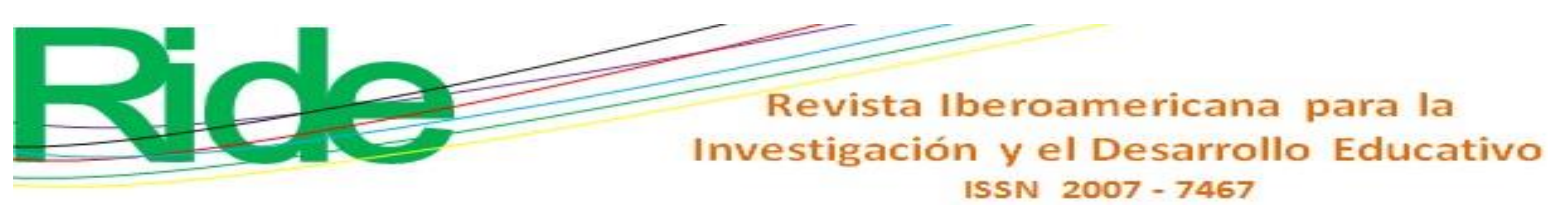

sección de números y algunas palabras afines que se utilizaron en la construcción de los videos en lengua de señas con subtítulos (Serafín, 2015, pp. 224-237).

Respecto a la literatura y algunos trabajos recientes que sirven aquí como marco de referencia, se encontró que, en el 2018, el juego educativo MatLibras fue utilizado para enseñar números en lengua de señas brasileña. Según Pontes, Pinheiro y Furlan (2018), MatLibras tiene un futuro prometedor en entornos educativos, pues fomenta la motivación del aprendiz a través de un entrenamiento previo a la competencia promovida por el software mismo, el cual, además, posee una arquitectura modular que permite configurar el juego para otras lenguas de señas. Por otro lado, en 2015 se realizó un estudio sobre el diseño y evaluación de un prototipo multimedia para la enseñanza de la aritmética en una población estudiantil de personas sordas en Tailandia, en específico en pequeños de siete años y en operaciones de conteo, sumas y restas. Los autores identificaron altos índices de motivación y fácil comprensión en el aprendizaje autónomo (Techaraungrong, Sukasakulchai, Kaewprapan y Murphy, 2015).

Un año atrás, en 2014, se emprendió un estudio con el fin de describir el desarrollo y la evaluación de un curso a distancia para personas sordas dedicado al aprendizaje de la informática y basado en un método avanzado del índice pedagógico que se adoptó en Eslovenia. Dicho curso incluía transmisiones de videos con subtítulos y videos en lengua de señas con intérpretes (Debevc, Stjepanovič y Holzinger, 2014). En esa misma línea, se encontró una iniciativa que fue patrocinada en el año 2013 por el Programa de Aprender a lo Largo de la Vida, del proyecto Leonardo da Vinci, en donde personas sordas de los países de Grecia, Chipre, Italia e Inglaterra debían estudiar con herramientas de la Web 2.0: blogs, wikis, redes sociales y la típica hipermedia, aunado a la lectura de los labios, videos en lengua de signos y otras actividades de aprendizaje para adquirir conocimientos de comercio electrónico, los estándares internacionales de contabilidad y afrontar la discalculia (Drigas, Vrettaros, Argiri y Bardis, 2013).

Finalmente, en 2010 se publicó un estudio sobre el mejoramiento del aprendizaje en estudiantes con sordera a partir de la lengua de signos y el texto; allí algunas barreras para aprender el texto de una lectura y el lenguaje de señas para los sordos fueron evidenciadas. De acuerdo con los autores, si se desean mejores desempeños tanto en entornos educativos formales e informales es necesario plantearse expectativas más altas (Borgna, Convertino, Marschark, Morrison y Rizzolo, 2010). 


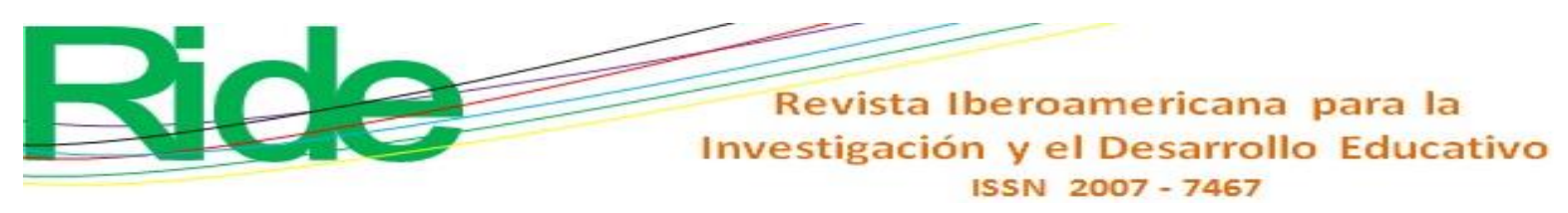

Tabla 1. Hipótesis de investigación.

\begin{tabular}{|l|l|}
\hline \multicolumn{1}{|c|}{$\begin{array}{c}\text { Hipótesis de investigación } \\
\text { Sección: Aritmética }\end{array}$} & \multicolumn{1}{c|}{$\begin{array}{c}\text { Hipótesis nula } \\
\text { Sección: Aritmética }\end{array}$} \\
\hline $\begin{array}{l}\mathrm{Hi}_{\text {oaycn: Se logró obtener evidencia de una }} \\
\text { mejoría en el aprovechamiento escolar en el } \\
\text { grupo experimental en comparación con el } \\
\text { grupo de control, con el uso y aplicación del } \\
\text { instrumento de medición. }\end{array}$ & $\begin{array}{l}\text { Ho oaycn: No se logró obtener evidencia de una } \\
\text { mejoría en el aprovechamiento escolar en el } \\
\text { grupo experimental en comparación con el } \\
\text { grupo de control, con el uso y aplicación del } \\
\text { instrumento de medición. }\end{array}$ \\
\hline
\end{tabular}

\section{Fuente: Elaboración propia}

El procedimiento de investigación se basó en comparar a dos grupos de investigación. Como se ha visto, al primero se le denominó grupo de control, donde está ausente la variable independiente relativa al objeto de aprendizaje en lengua de señas mexicana para sordos, y se mantiene el método tradicional utilizado para el aprendizaje de la aritmética en el modelo educativo bicultural-bilingüe para personas sordas. Mientras que el grupo experimental recibe el estímulo experimental con la presencia de la variable independiente. En ambos grupos, sin embargo, está presente la variable dependiente, que se define como el aprovechamiento escolar, que es la que se medirá a través de la comparación de estos dos grupos que son similares entre sí e equivalentes, y a través de la técnica de emparejamiento, a saber, que tengan conocimientos previos de la aritmética.

Para llevar a cabo la investigación se diseñó y desarrolló el objeto de aprendizaje en lengua de señas mexicana para sordos conocido como Mate con señas, de cual se obtuvo el Certificado de Registro Público del Derecho de Autor No. 03-2016-081911254700-01 en el Instituto Nacional del Derecho de Autor, perteneciente a la Secretaría de Cultura del Gobierno Federal. Se decidió desarrollar este objeto de aprendizaje digital para dispositivos móviles mediante la metodología de ingeniería de software ágil híbrido. Así, se organizó a cuatro grupos de trabajo que tuvieron el rol de desarrollo, control de cambios, cliente y pruebas. Se siguió el ciclo de vida de forma iterativa y siempre presentando el prototipo al usuario final para su retroalimentación (Leiva y Villalobos, 2015). Las suites de Android Studio y Adobe Acrobat fueron utilizadas per se para su diseño y desarrollo, con la finalidad de que operara en tabletas y teléfonos inteligentes con sistema operativo Android. En la figura 2 se muestra el objeto de aprendizaje en lengua de señas mexicana para sordos. 


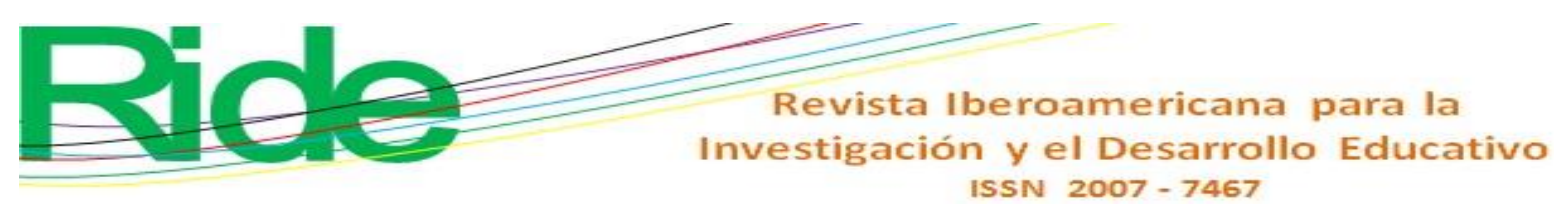

Figura 2. Objeto de aprendizaje digital (Mate con señas)

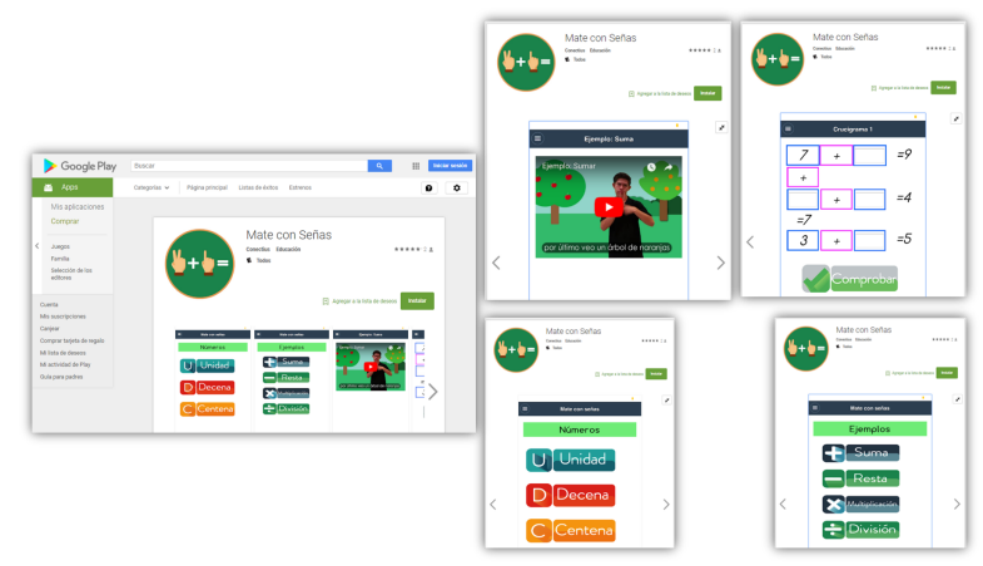

Fuente: Elaboración propia

Apoyándose en lo que se menciona en cuanto a que en una sociedad con cambios notables y con desarrollos tecnológicos disponibles se demandan ajustes significativos en los sistemas de educación, en términos generales, el uso sistemático y coordinado de diferentes tecnologías como dispositivos móviles, tabletas o teléfonos inteligentes, y de aplicaciones como GeoGebra, WolframAlpha, Khan Academy, pueden contribuir en la construcción del conocimiento del estudiante (Santos, 2015). Y es entonces que se consideró la propuesta pedagógica digital de las estrategias de intervención que se sugieren para las matemáticas para personas con discapacidad auditiva por parte de Cardona, Arámbula y Vallarta (2014, pp. 41-48). Por lo que se muestran las secciones del objeto de aprendizaje en lengua de señas mexicana para sordos y las actividades propuestas que se recomiendan para los números, sus relaciones y operaciones mediante videos en lengua de señas mexicana con subtítulos en español con intérpretes que utilizan la dactilología e ideogramas.

En la figura 3 se utiliza la dactilología y los ideogramas para explicar que la aritmética es una rama de las matemáticas que estudia a los números y a las operaciones que se realizan con ellos. 


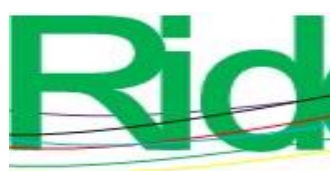

\section{Revista Iberoamericana para la Investigación y el Desarrollo Educativo ISSN $2007-7467$}

Figura 5. Concepto de decenas. Ejemplos con imágenes-números
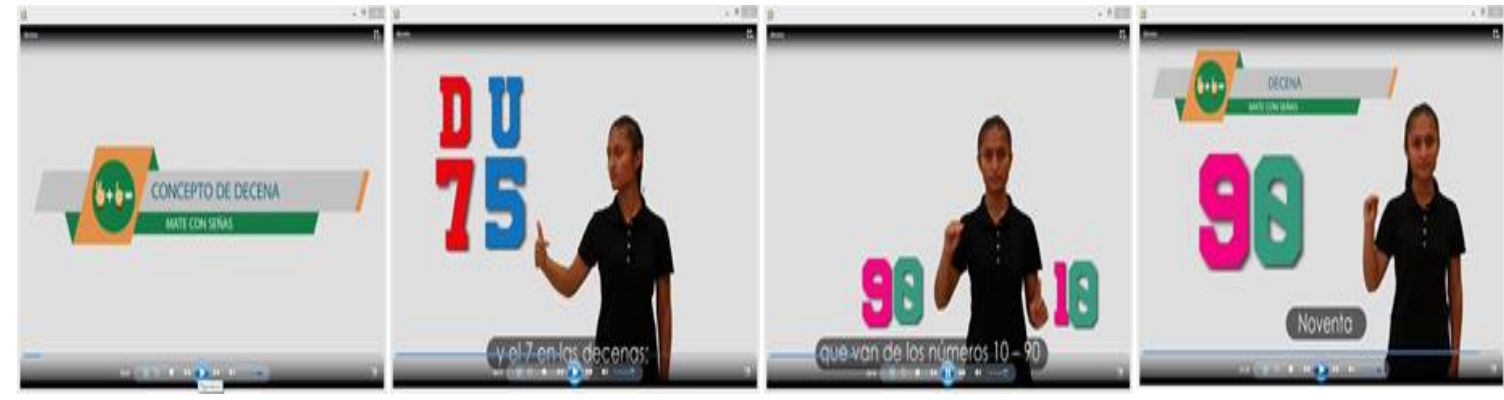

Fuente: Elaboración propia

En la figura 6, mientras tanto, se explica el concepto de las centenas y la relación entre imágenes y los números.

Figura 6. Concepto de centenas. Ejemplos con imágenes-números
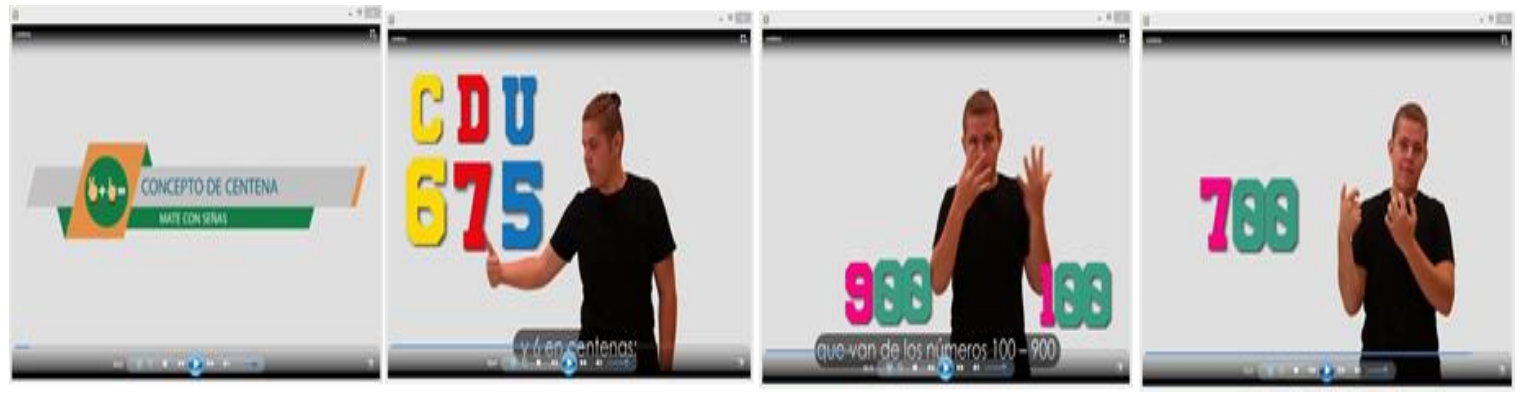

Fuente: Elaboración propia

En la figura 7, y dada la recomendación de propiciar en las niñas y los niños sordos que se acerquen al conocimiento con la representación gráfica de los números una serie de ejercicios y ejemplos que irán aumentando en dificultad, se inicia con la primera operación, referente a la adición; allí se aprovechan situaciones cotidianas, juegos y actividades rutinarias para realizar estas operaciones, a través de la composición de cantidades y números correspondientes.

Figura 7. Concepto y ejemplos de la adición (sumar). Ejemplos con imágenes-números y números-números
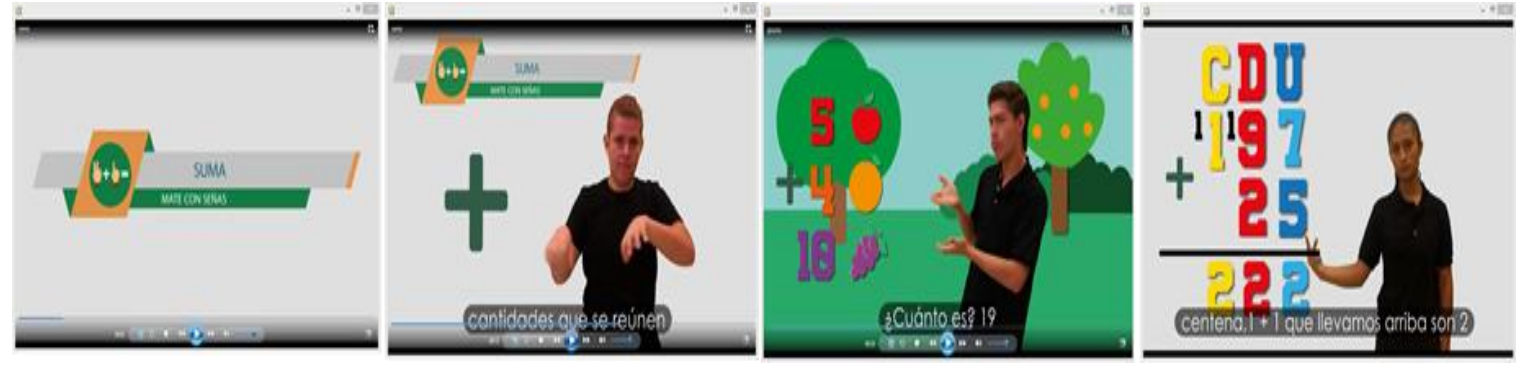

Fuente: Elaboración propia 


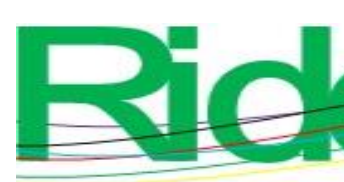

\section{Revista Iberoamericana para la Investigación y el Desarrollo Educativo ISSN $2007-7467$}

En la figura 8 se describe el concepto de la sustracción y varios ejemplos.

Figura 8. Concepto y ejemplos de la sustracción (restar). Ejemplos con imágenes-números y números-números
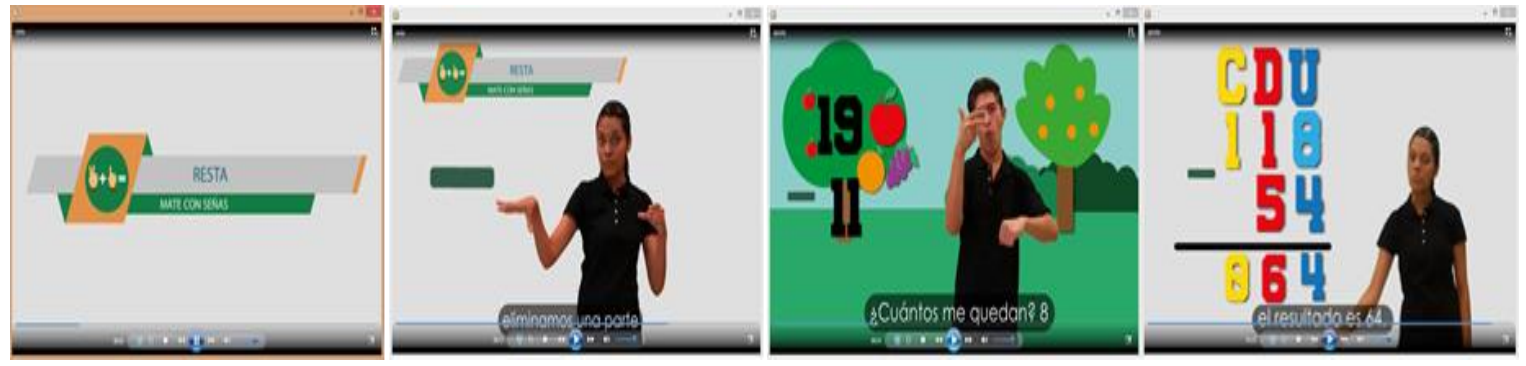

Fuente: Elaboración propia

Aunado a ello, en la figura 9 se describe el concepto de la multiplicación y una serie de ejemplos con mayor complejidad.

Figura 9. Concepto y ejemplos de la multiplicación (multiplicar). Ejemplos con imágenesnúmeros y números-números
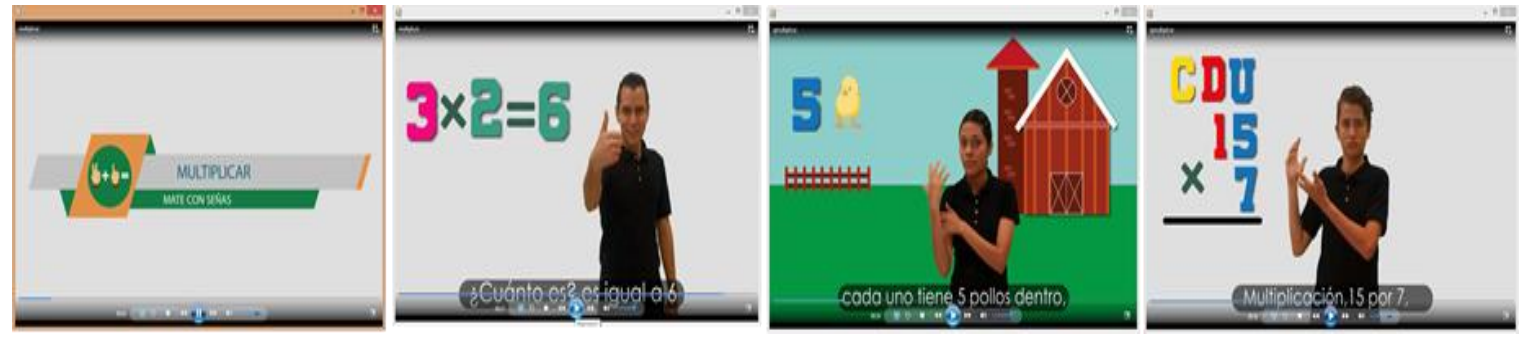

Fuente: Elaboración propia.

En la figura 10, por último, se muestra el concepto de la división y varios ejemplos que fomentan la comprensión y construcción del conocimiento matemático a través de las relaciones entre imágenes y números, así como de números con números. 


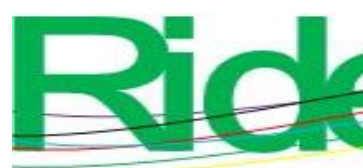

\section{Revista Iberoamericana para la Investigación y el Desarrollo Educativo ISSN $2007-7467$}

Figura 10. Concepto y ejemplos de la división (dividir). Ejemplos con imágenes-números y números-números

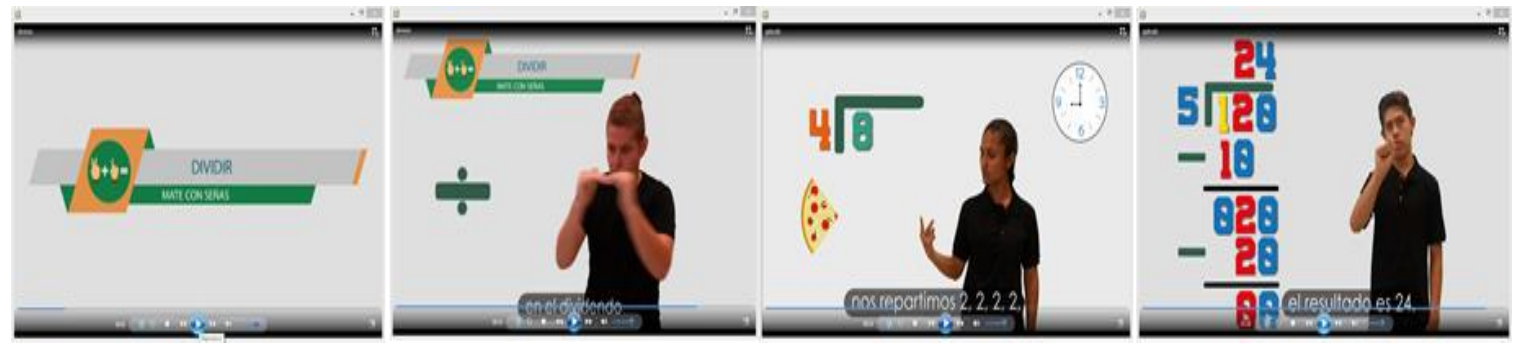

Fuente: Elaboración propia

También, se diseñó el instrumento que sirvió como prueba estandarizada y que se usó para medir el aprovechamiento escolar en la aritmética. Fue diseñado considerando el mapa curricular y la dosificación de los aprendizajes esperados para los tres primeros grados de la primaria en la asignatura de matemáticas. Se presentó como un cuadernillo de trabajo con las cuatro operaciones a evaluar y se incorporó una sección de crucigramas numéricos de operaciones aritméticas. Esta se aplicó en dos momentos diferentes en cada grupo de investigación.

Cabe señalar que la variable dependiente se determinó cuantitativamente en ambos grupos de investigación. Este indicador es utilizado para medir el aprovechamiento escolar en asignaturas de ciencias; por ello es por lo que se utilizó.

Hay un estudio reciente publicado por Sanhueza, Bravo, Fáundez y Utreras (2018), en donde se buscó conocer el impacto que tienen las TIC en estudiantes de física de educación media, dependientes del Ministerio de Educación de Chile, que reportó una ganancia conceptual de Hake de media a moderada. En ese mismo país, pero en 2016, se llevó a cabo una propuesta que tenía como objetivo elaborar proyectos de mejoramiento para la enseñanza de las ciencias en la Universidad de Concepción y donde se verificó la eficacia de la adquisición de aprendizaje significativo mediante el factor Hake (Bravo, Ramírez, Fáundez y Astudillo, 2016). En esa misma tónica, en el estudio de Barragán (2016) se midió el aprovechamiento reportado por medio de la ganancia normalizada o factor Hake, resultado de la aplicación de los criterios operativos de los correspondientes principios que se utilizaron para el desarrollo y aplicación de una estrategia didáctica, y que generó una mejora continua en los aprendizajes.

Siguiendo dichos ejemplos, en este trabajo se aplicó el mismo instrumento de medición de manera simultánea en ambos grupos: prueba previa y prueba posterior. Además, los resultados obtenidos fueron validados a través del método de la prueba estadística parametrizada conocida como $t$-Student; por último, la confiabilidad o fiabilidad del instrumento fue evaluada mediante el 


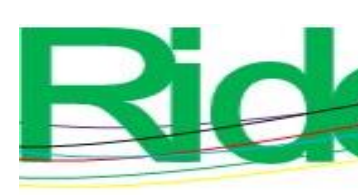

\section{Revista Iberoamericana para la Investigación y el Desarrollo Educativo ISSN $2007-7467$}

Figura 11. Gráfica con líneas de tendencia lineal. Grupo de control. Sustracción

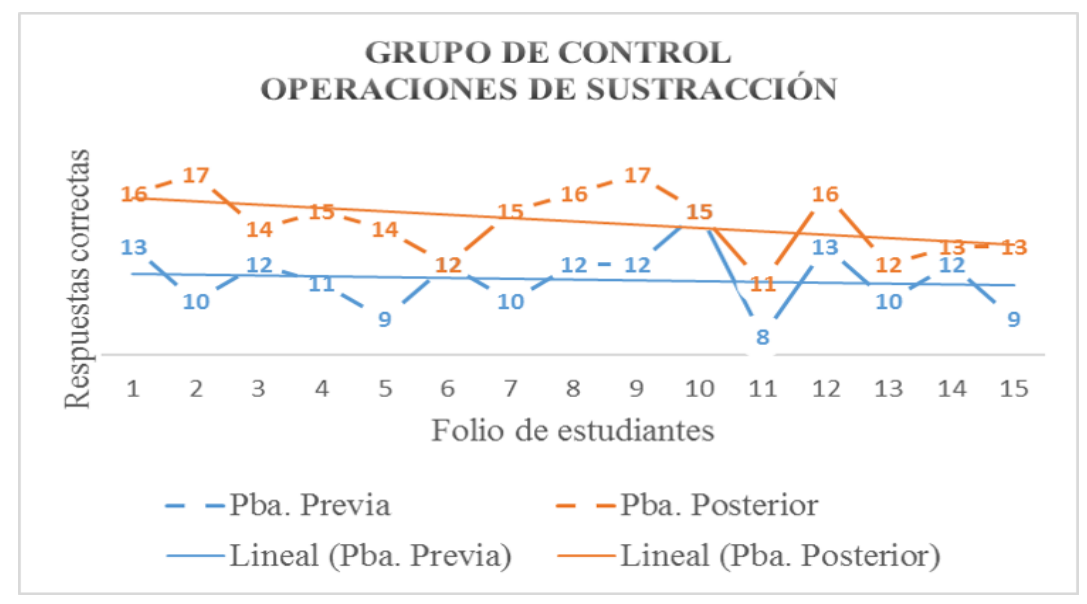

Fuente: Elaboración propia

La media y la varianza muestran la comparación de las dos pruebas realizadas y en los dos momentos diferentes del experimento obtenidas en la prueba $t$-Student.

Aunque favorables los resultados, el logro o mejora en el aprendizaje es significativamente bajo. Para realizar la comprobación de la hipótesis de investigación se consideró el nivel de significancia, que es alto, y la distribución muestral, al aplicar la prueba parametrizada como medida estabilizadora del experimento.

Por otro lado, en la tabla 3 se muestran los resultados de la prueba parametrizada $t$-Student y la ganancia normalizada Hake para el grupo experimental.

Se observó que, para este segundo grupo, la recolección de datos ofrece un grado de confiabilidad muy consistente y coherente con los resultados obtenidos al presentar una correlación positiva débil del 0.3395, y al mantener una relación estrecha con la validez del instrumento de medición de 99.99958 \% . La ganancia normalizada es moderada. 


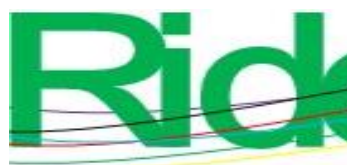

Revista Iberoamericana para la Investigación y el Desarrollo Educativo ISSN $2007-7467$

Tabla 3. Prueba $t$-Student y de ganancia normalizada Hake. Grupo experimental. Sustracción

\begin{tabular}{|l|r|r|r|}
\hline & Prueba previa & \multicolumn{1}{c|}{$\begin{array}{c}\text { Prueba } \\
\text { posterior }\end{array}$} & $\begin{array}{r}\text { Factor } \\
\text { Hake }\end{array}$ \\
\hline Media & 10.53333333 & 14.73333333 & 0.04694486 \\
\hline Varianza & 5.266666667 & 1.923809524 & \\
\hline Observaciones & 0.339592125 & & \\
\hline Coeficiente de correlación de Pearson & 0 & & \\
\hline Diferencia hipotética de las medias & -14 & & \\
\hline Grados de libertad & 0.00000210 & & \\
\hline Estadístico $t$ & 1.761310136 & & \\
\hline$P(T<=t$ ) una cola & 0.00000420 & & \\
\hline Valor crítico de $t$ (una cola) & 2.144786688 & & \\
\hline$P(T<=t)$ dos colas & & \\
\hline Valor crítico de $t$ (dos colas) & & \\
\hline
\end{tabular}

Fuente: Elaboración propia

En este caso, gráficamente las líneas de tendencia lineal se ven estables y casi paralelas tanto en la prueba previa como en la prueba posterior. La media y la varianza obtenidas son ligeramente mejores a las reportadas en el grupo de control y muestran la comparación de las dos pruebas realizadas en los dos momentos del experimento. También se comprueba la hipótesis de investigación, considerando el nivel de significancia obtenida en este grupo, que es alto y superior al del grupo de control, y la distribución muestral de los valores obtenidos de esta población: sí se observa una mejora moderada a alta en el aprendizaje de la aritmética en el grupo experimental en comparación con el grupo de control. 


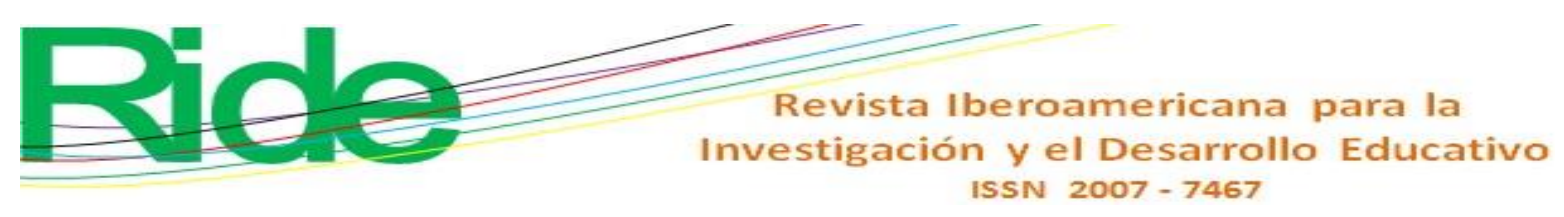

Figura 12. Gráfica con líneas de tendencia lineal. Grupo experimental. Sustracción

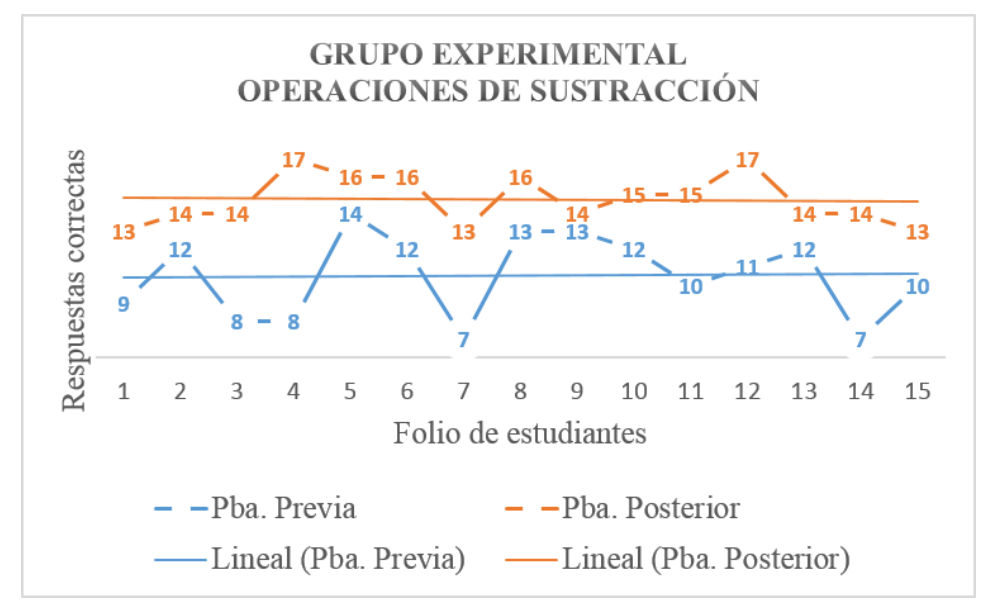

Fuente: Elaboración propia

\section{Resultados}

Después de haber realizado el análisis cuantitativo de los datos obtenidos en la investigación durante el periodo comprendido de septiembre a noviembre de 2018, a continuación se presentan los hallazgos encontrados a través de la inferencia correlacional de datos estadísticos y de los resultados obtenidos experimentalmente en nuestra población de personas sordas que se encuentran cursando el tercer año de la primaria del Centro de Atención Múltiple Helen Keller, ubicado en la capital del estado de Querétaro, México, especializado en la atención de niñas y niños con sordera en los niveles de preescolar, primaria y secundaria.

Los resultados ponen de manifiesto que sí se logró nuestro objetivo principal de la investigación: al obtener la evidencia de que en el grupo experimental, en donde estuvo presente el objeto de aprendizaje en lengua de señas mexicana para sordos, se logró una mejora en el aprovechamiento escolar en el aprendizaje de las cuatro operaciones aritméticas en comparación con el grupo de control.

En la tabla 4 se muestran los resultados de inferencia estadística para los dos grupos de investigación y las variables de aprendizaje evaluadas de la sección de operaciones aritméticas.

En ambos grupos de investigación, los resultados obtenidos en el indicador estadístico de la media $(\bar{X})$ fue mejor en la prueba posterior que en la prueba previa. Es de resaltar que en el grupo experimental la dirección del coeficiente de correlación de Pearson $\left(r_{x y}\right)$ fue positiva, es decir, se acercó a 0.50, que es una correlación positiva media, y el valor numérico refleja la magnitud de la correlación que, comparada con la significancia $P(T \leq t)$, supera por mucho el nivel de 


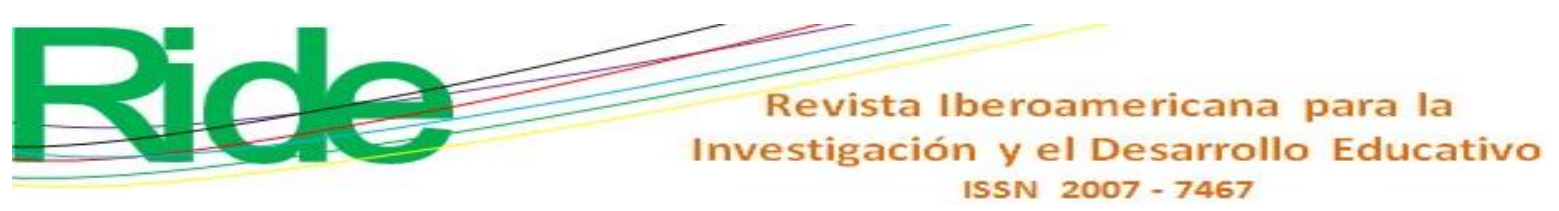

significancia planteado del 0.05 en el grupo experimental en comparación con el grupo de control. Al hallarse una confianza en que la correlación es verdadera al ser superior $95 \%$ y $5 \%$ de probabilidad de error. En el grupo de control se presentó un signo negativo, lo que cambió el sentido de la dirección de la correlación a negativa media al acercarse a -0.50 , con lo cual afectó a la variable de aprendizaje de la multiplicación, y la división presentó un aprovechamiento escolar más limítrofe. Por lo que se infiere que en el grupo de control se encontró una mejoría baja en el aprendizaje de la aritmética, al no contar con la presencia del objeto de aprendizaje en lengua de señas mexicana para sordos. Habrá que considerar, asimismo, que en el grupo experimental el orden en el cual se presentó una mejoría moderada fue en la multiplicación, la adición, la sustracción y finalmente en la división; en contraposición al orden que presentó el grupo de control, en donde se halló una mejoría baja empezando con la sustracción, multiplicación, adición y división. 


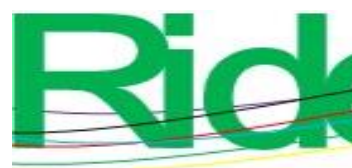

Revista Iberoamericana para la Investigación y el Desarrollo Educativo ISSN $2007-7467$

Tabla 4. Resultados por grupo de investigación y variable de aprendizaje evaluada Medición de la mejora del aprendizaje de la aritmética. Operaciones aritméticas

\section{Grupo de investigación de control}

\begin{tabular}{|c|c|c|c|c|c|c|c|c|}
\hline Variable & \multicolumn{2}{|c|}{$\begin{array}{l}\text { Prueba } \\
\text { previa }\end{array}$} & \multicolumn{2}{|c|}{$\begin{array}{l}\text { Prueba } \\
\text { Posterior }\end{array}$} & \multicolumn{3}{|c|}{$\begin{array}{c}\text { Prueba t para medias de dos } \\
\text { muestras emparejadas }\end{array}$} & \multirow{2}{*}{$\begin{array}{c}\text { Ganancia } \\
\text { normalizada } \\
\text { Factor } \boldsymbol{g}\end{array}$} \\
\hline $\begin{array}{l}\text { Operaciones } \\
\text { aritméticas }\end{array}$ & $\bar{X}$ & $\sigma^{2}$ & $\bar{X}$ & $\sigma^{2}$ & $r_{x y}$ & $\boldsymbol{t}$ & $\begin{array}{l}P(T \leq t) \\
\text { dos colas }\end{array}$ & \\
\hline Adición & 14.00 & 4.57 & 16.20 & 5.02 & 0.8491 & -7.05 & 0.0000057 & 0.0255814 \\
\hline Sustracción & 11.20 & 3.45 & 14.40 & 3.54 & 0.4449 & -6.28 & 0.0000200 & 0.0360360 \\
\hline Multiplicación & 10.53 & 6.55 & 12.86 & 2.83 & -0.4295 & -2.49 & 0.0256012 & 0.0260805 \\
\hline División & 10.66 & 1.52 & 11.33 & 5.38 & 0.3409 & -1.16 & 1.2653555 & 0.0074627 \\
\hline \multicolumn{9}{|c|}{ Grupo de investigación experimental } \\
\hline Variable & \multicolumn{2}{|c|}{$\begin{array}{l}\text { Prueba } \\
\text { previa }\end{array}$} & \multicolumn{2}{|c|}{$\begin{array}{c}\text { Prueba } \\
\text { Posterior }\end{array}$} & \multicolumn{3}{|c|}{$\begin{array}{c}\text { Prueba t para medias de dos } \\
\text { muestras emparejadas }\end{array}$} & $\begin{array}{l}\text { Ganancia } \\
\text { normalizada }\end{array}$ \\
\hline $\begin{array}{l}\text { Operaciones } \\
\text { aritméticas }\end{array}$ & $\bar{X}$ & $\sigma^{2}$ & $\bar{X}$ & $\sigma^{2}$ & $r_{x y}$ & $t$ & $\begin{array}{l}P(T \leq t) \\
\text { dos colas }\end{array}$ & Factor $g$ \\
\hline Adición & 13.80 & 6.02 & 18.00 & 2.42 & 0.4293 & -7.15 & 0.0000049 & 0.0487239 \\
\hline Sustracción & 10.53 & 5.26 & 14.73 & 1.92 & 0.3395 & -7.25 & 0.0000042 & 0.0469449 \\
\hline Multiplicación & 10.93 & 2.78 & 15.40 & 5.54 & 0.1528 & -6.48 & 0.0000144 & 0.0501497 \\
\hline División & 11.33 & 2.38 & 14.13 & 3.98 & 0.0541 & -4.41 & 0.0005857 & 0.0315789 \\
\hline
\end{tabular}

Nota: $\bar{X}=$ Media; $\sigma^{2}=$ Varianza; $r_{x y}=$ Coeficiente de correlación de Pearson; $t=$ Estadístico $t$; $P(T \leq t)=$ Prueba de hipótesis; Factor $g=$ Ganancia normalizada o factor Hake.

\section{Fuente: Elaboración propia}

Con esta información se demostró que la hipótesis de investigación se confirma en el sentido de que sí se observó un aprovechamiento escolar moderado y superior en el aprendizaje de la aritmética en las operaciones de adición, sustracción y multiplicación en el grupo experimental en comparación con el grupo de control; no así, sin embargo, en la operación de división, en donde no se cumplió en el sentido de que se observó un desempeño bajo, pero finalmente un aprovechamiento escolar. Además, se logra contestar a la pregunta de investigación para esta sección de operaciones aritméticas, al afirmar que sí se logran los aprendizajes esperados o la mejoría de estos en el aprovechamiento escolar de la aritmética en personas sordas con el uso de tecnología educativa. Y como resultado de ello sí se logró adquirir las competencias matemáticas 


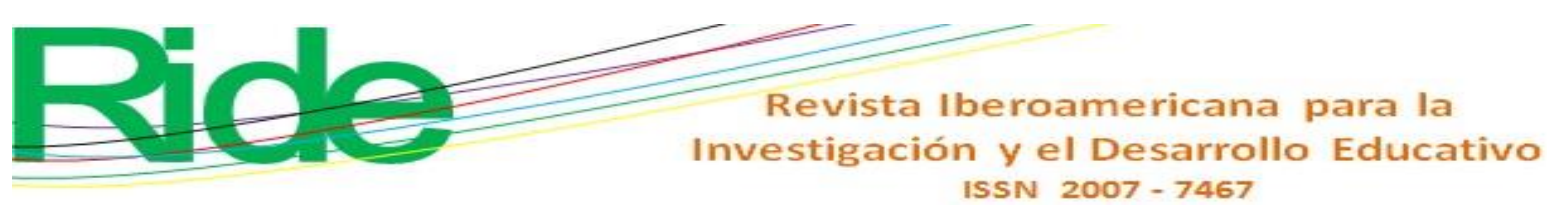

al verse favorecidas con el uso de la tecnología. Adicional a esta primera sección, se incorporó al estudio la sección de crucigramas numéricos de operaciones aritméticas como un elemento lúdicopedagógico.

Por lo tanto, se aceptan con gran expectativa los resultados que a continuación se muestran en la tabla 5. Los resultados de inferencia estadística para los dos grupos de investigación y las variables de aprendizaje evaluadas para esta sección.

Se observó que en ambos grupos de investigación los resultados obtenidos en el indicador estadístico de la media $(\bar{X})$ fue mejor en la prueba posterior que en la prueba previa. En este caso también es de subrayar que en el grupo experimental la dirección del coeficiente de correlación de Pearson $\left(\boldsymbol{r}_{x y}\right)$ fue positiva, es decir, se acercó en la operación de la adición a 0.50, en la sustracción y división sobrepasan a los 0.50 , considerándose como una correlación positiva media, y finalmente la multiplicación casi llega a ser una correlación positiva considerable. El valor numérico refleja la magnitud de la correlación comparada con la significancia $P(T \leq t)$. Supera en mucho el nivel de significancia del 0.05 planteado en el grupo experimental comparado con el grupo de control. 


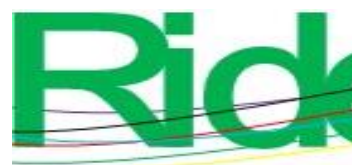

\section{Revista Iberoamericana para la Investigación y el Desarrollo Educativo ISSN $2007-7467$}

Con esta información probamos que se cumple la hipótesis de investigación para las cuatro operaciones aritméticas a través de los crucigramas numéricos; en el sentido de que sí se observó un desempeño moderado a alto en el grupo experimental en comparación con el grupo de control. También confirmamos que se cumple con el objetivo principal de la investigación. Sobresale que la sección de jugar del objeto de aprendizaje en lengua de señas mexicana para sordos fue bien aceptada y provocó los mejores indicadores en el aprovechamiento escolar en el aprendizaje de la aritmética en el grupo experimental de investigación. De igual manera, se contesta a la pregunta de investigación para esta sección, al afirmar que sí se logran los aprendizajes esperados o la mejoría de estos en la aritmética en la sección de crucigramas numéricos de operaciones aritméticas en personas sordas en el grupo experimental, comparado con los hallazgos del grupo de control.

En las figuras 13, 14, 15 y 16 se visualizan de forma gráfica los resultados obtenidos en los dos grupos de investigación en cada una de las variables de operaciones aritméticas medidas, tanto lo obtenido en las pruebas previas como en las pruebas posteriores con un mismo instrumento de investigación.

Figura 13. Resultados obtenidos. Adición

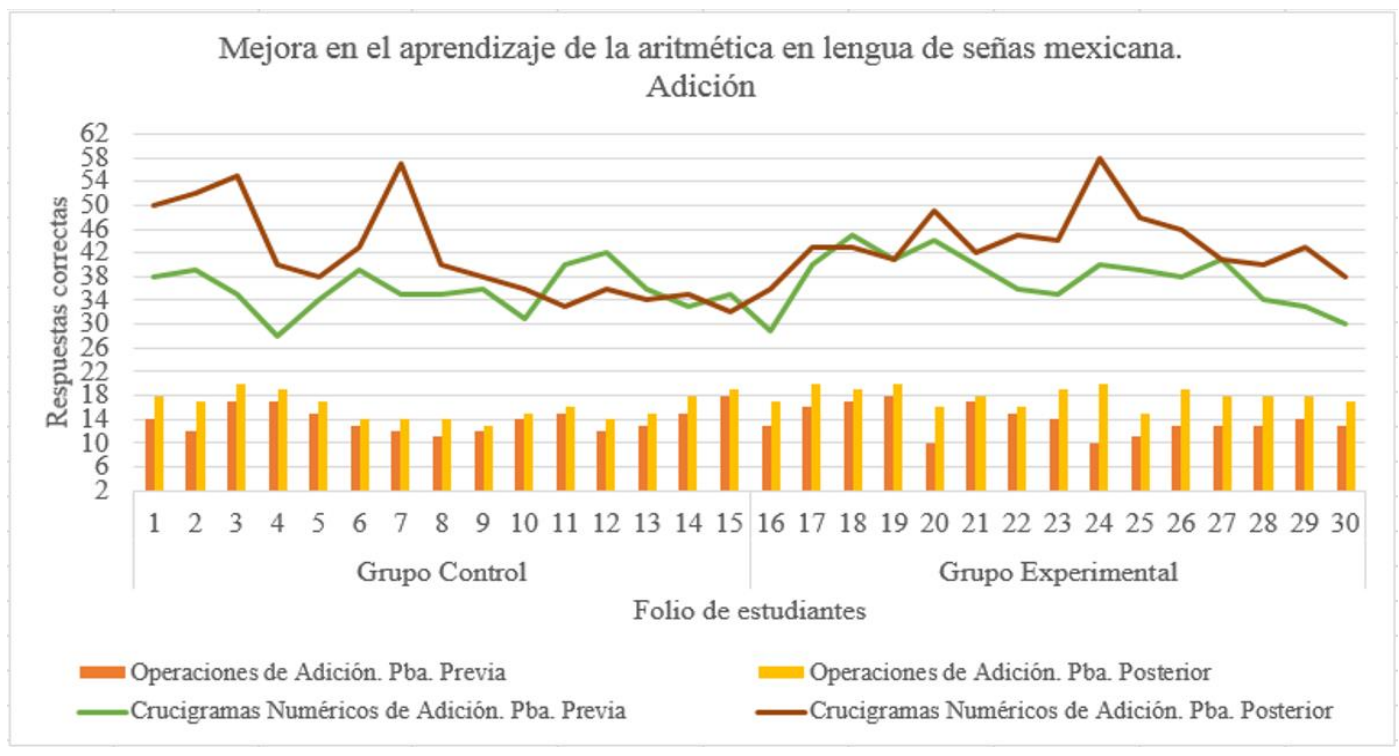

Fuente: Elaboración propia 


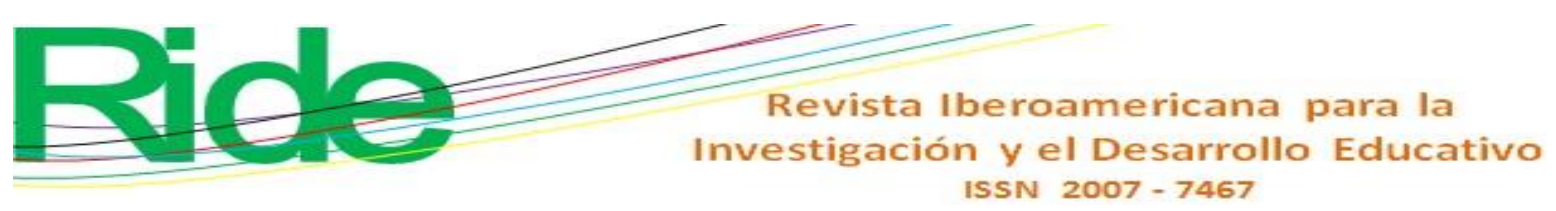

Figura 14. Resultados obtenidos. Sustracción

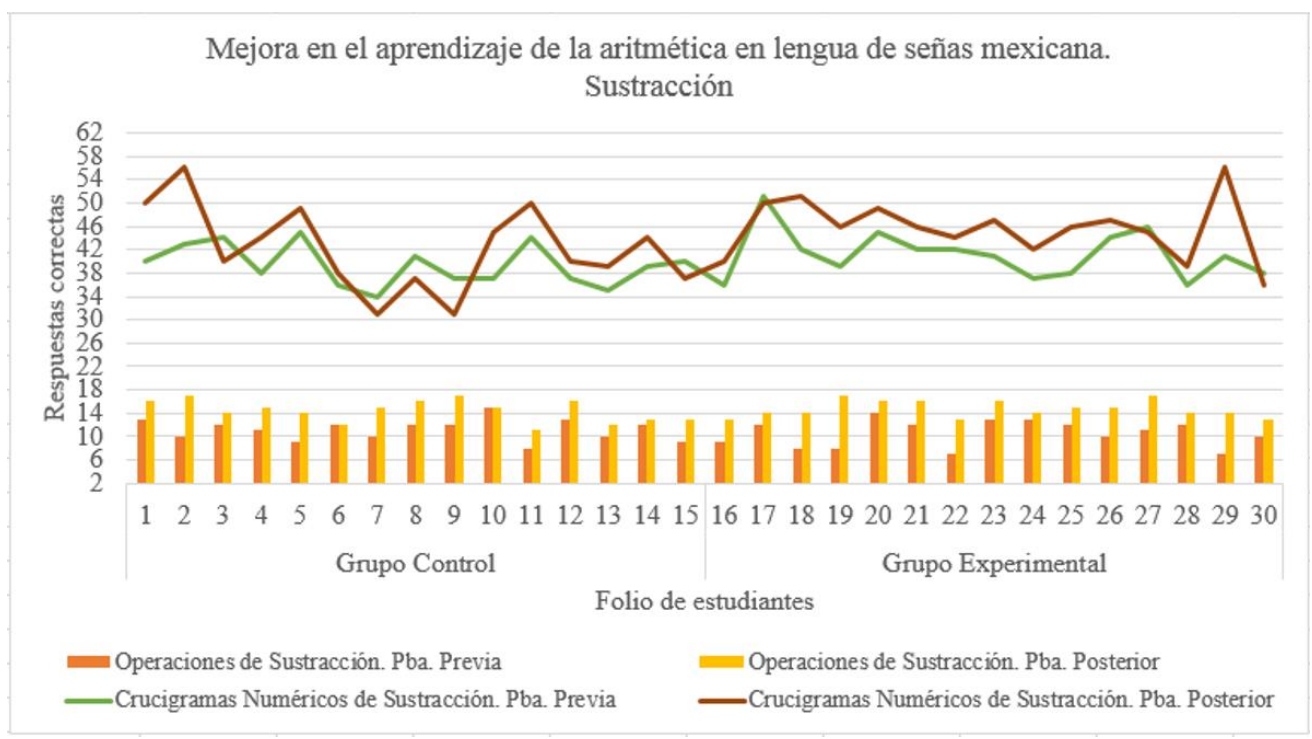

Fuente: Elaboración propia

Figura 15. Resultados obtenidos. Multiplicación

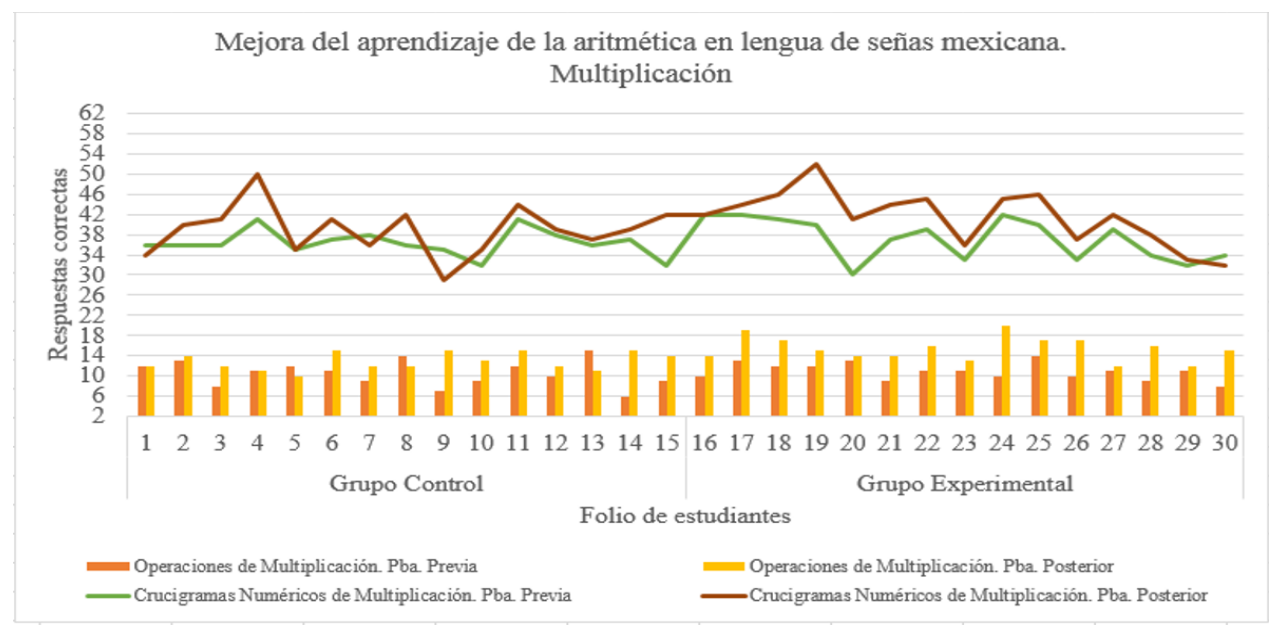

Fuente: Elaboración propia 


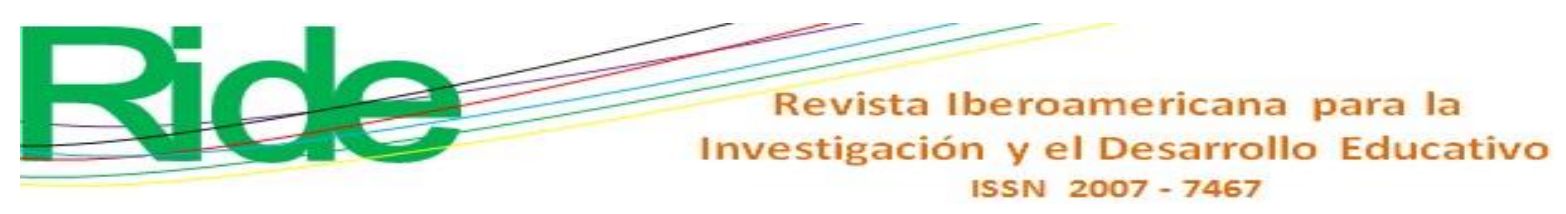

Figura 16. Resultados obtenidos. División

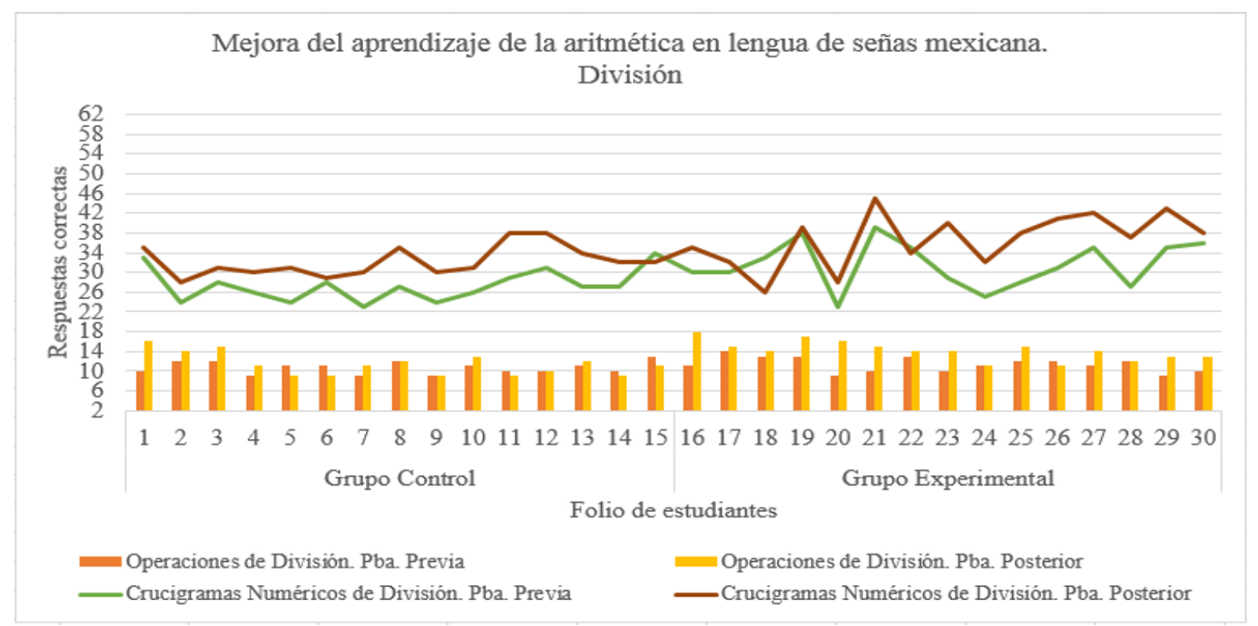

Fuente: Elaboración propia

Queda como reflexión que el manejo de crucigramas numéricos representó para ellos, para los alumnos, un reto interesante y los motivó a obtener los mejores resultados. Es decir, están dispuestos a experimentar otras estrategias educativas diferentes a las habituales que les permitan un mejor aprovechamiento escolar. Este componente se incorporó tanto en el instrumento de recolección de datos como en el objeto de aprendizaje en lenguas de señas mexicana para sordos utilizado.

\section{Discusión}

Dado lo reportado en el contexto internacional, se coincide en el sustento teórico del aprovechamiento de las TIC mediante los nuevos entornos de aprendizaje, que se ven favorecidos por el uso de los nuevos medios de comunicación. Con relación a los espacios de aprendizaje basados en juegos, nuestra investigación utiliza crucigramas numéricos y ejercicios interactivos para el aprendizaje de las operaciones aritméticas que se realizan con los números en comparación con el juego educativo MatLibras, que solo enseña los números vía juegos (Pontes et al., 2018). Nosotros enseñamos, además, los números y las operaciones aritméticas con videos en lengua de señas mexicana con subtítulos en español. También se coincide con el trabajo realizado por Techaraungrong et al. (2015) en Tailandia, con una población estudiantil de personas sordas de siete años, quienes con multimedia enseñaron el conteo, la suma y las restas. Este artículo considera espacios de aprendizaje basados en el aprendizaje personalizado y autónomo. Nuestra investigación aporta también a un sector de esta población ligeramente mayor en edad, lo que permitió completar las operaciones de multiplicación y división, y facilita la personalización del 


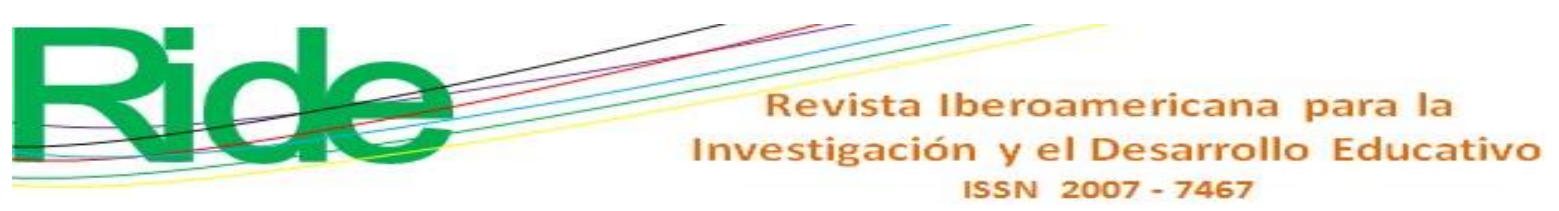

aprendizaje al utilizar el teléfono celular, la tableta y la computadora personal para el uso y aplicación del objeto de aprendizaje en lengua de señas mexicana para sordos. De forma análoga a los estudios hechos en Eslovenia, Grecia, Chipre, Italia e Inglaterra, en donde se aprovecha el diseño de cursos a distancia con la utilización de componentes de la Web 2.0, videos en lengua de señas con intérpretes dirigidos a entornos de aprendizaje formales e informales con énfasis en MOOC, espacios web colaborativos y las redes sociales, aquí se recurre al uso de la tecnología en la educación para atender la diversidad de necesidades educativas específicas.

Sobresale el involucramiento y participación de las personas sordas de manera activa en la educación. Ellos mismos participaron tanto en el diseño y el desarrollo del objeto de aprendizaje: se convirtieron en los constructores y usuarios de esta tecnología pedagógica en entornos educativos modernos.

\section{Conclusiones}

Esta investigación aportó a la comunidad educativa y a quienes atienden la diversidad de las necesidades específicas del estudiante con déficit auditivo en su aprendizaje de la aritmética la evidencia de que se encontró una mejora moderada en el aprovechamiento escolar con el apoyo de una tecnología educativa diseñada e implementada en un entorno de aprendizaje apropiado para las prácticas de inclusión educativa. La tecnología aplicada a la educación fomenta el autoaprendizaje; la cobertura se amplía a otras latitudes y es mayor el número de beneficiarios.

Resultado del análisis estadístico inferencial y del nivel de significancia en la distribución muestral obtenidos, se observó que el grupo experimental presentó una mejora en las cuatro operaciones aritméticas en comparación con el grupo de control.

Después de haber realizado este estudio, se identificó un valor teórico con una implicación práctica acorde a los nuevos entornos educativos, los medios de comunicación y las tecnologías aplicadas a la educación.

Finalmente, se contribuyó a que miembros de la comunidad sorda que residen en Querétaro participaran activamente en esta investigación educativa; y dejó en claro tanto para ellos como para nosotros la conveniencia de favorecer el aprendizaje con el uso de tecnología como una estrategia diferenciadora en favor de su aprovechamiento escolar, formación académica e inclusión educativa. 


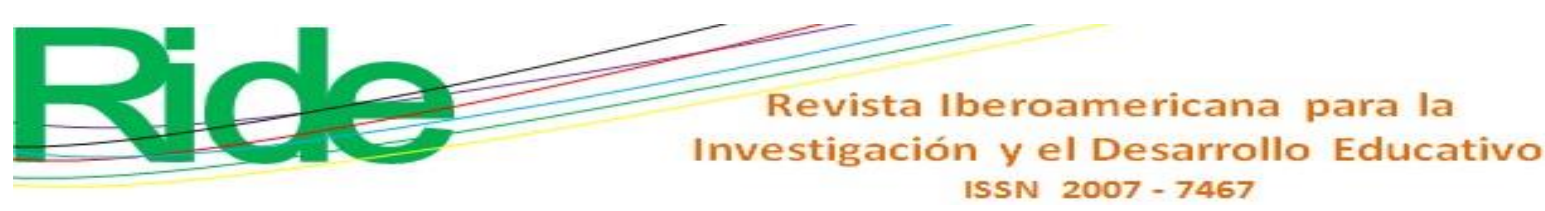

\section{Referencias}

Barragán Gómez, A. L. (2016). Desarrollo y aplicación de una estrategia didáctica para la integración del conocimiento a la enseñanza de la física en ingeniería. Innovación Educativa., 16(71), 133-155.

Borgna, G., Convertino, C., Marschark, M., Morrison, C. y Rizzolo, K. (2010). Enhancing Deaf Students' Learning from Sign Language and Text: Metacognition, Modality, and Effectiveness of Content Scaffolding. Journal of Deaf Studies and Deaf Education, 16(1), 79-100. doi:10.1093/deafed/enq036

Bravo, A., Ramírez, G. P., Fáundez Araya, C. A. y Astudillo, H. F. (2016). Propuesta didáctica constructivista para la adquisición de aprendizajes significativos en física de fluidos. Formación Universitaria., 9(2), 105-114. doi:10.4067/s0718-50062016000200012

Cámara de Diputados. (2018). Ley General para la Inclusión de las Personas con Discapacidad. México: Cámara de Diputados. Recuperado de http://www.diputados.gob.mx/LeyesBiblio/pdf/LGIPD_120718.pdf.

Cardona, A. L., Arámbula, L. M. y Vallarta, G. M. (2014). Estrategias de atención para las diferentes discapacidades. Manual para padres y maestros. Ciudad de México, México: Editorial Trillas.

Debevc, M., Stjepanovič, Z. and Holzinger, A. (2014). Development and evaluation of an elearning course for deaf and hard of hearing based on the advanced Adapted Pedagogical Index method. Interactive Learning Environments, 35-50.

Díaz, Y., Baena, M. A., y Baena, G. R. (2018). Nuevos escenarios de aprendizaje, un reto pedagógico. Revista Atlante: Cuadernos de Educación y Desarrollo. Recuperado de https://www.eumed.net/rev/atlante/2018/05/nuevos-escenarios-aprendizaje.html.

Drigas, A., Vrettaros, J., Argiri, K. and Bardis, N. (2013). Web 2.0 Learning Strategies for Disabled Students. Journal of Applied Mathematics \& Bioinformatics, 3(4), 125-140. Retrieved from https://www.researchgate.net/profile/Athanasios_Drigas/publication/280712713_Web_20 _Learning_Strategies_for_Disabled_Students/links/55c1f30d08aed9dff2a61033/Web-20Learning-Strategies-for-Disabled-Students.pdf.

Escudero, A., y Núñez, A. (2019). Fundamentos teóricos para la transformación de los «Massive Open Online Courses» hacia «Customizable Open Online Courses» (CzOOC). EDMETIC, Revista de Educación Mediática y TIC, 8(2), 129-149. Recuperado de https://doi.org/10.21071/edmetic.v8i2.10988. 


\section{Revista Iberoamericana para la Investigación y el Desarrollo Educativo ISSN 2007 - 7467}

\begin{tabular}{|c|c|}
\hline Rol de Contribución & Autor (es) \\
\hline Conceptualización & Juan José Rodríguez Peña \\
\hline Metodología & $\begin{array}{l}\text { Juan José Rodríguez Peña (principal) y Graciela Gerarda Ayala Jiménez } \\
\text { (apoyo) }\end{array}$ \\
\hline Software & Juan José Rodríguez Peña \\
\hline Validación & Graciela Gerarda Ayala Jiménez \\
\hline Análisis Formal & Juan José Rodríguez Peña (principal) y Manuel López Torrijo (apoyo) \\
\hline Investigación & Juan José Rodríguez Peña \\
\hline Recursos & Juan José Rodríguez Peña \\
\hline Curación de datos & Juan José Rodríguez Peña (principal) y Manuel López Torrijo (apoyo) \\
\hline $\begin{array}{l}\text { Escritura - Preparación del } \\
\text { borrador original }\end{array}$ & Juan José Rodríguez Peña \\
\hline Escritura - Revisión y edición & Graciela Gerarda Ayala Jiménez (apoyo) y Manuel López Torrijo (apoyo) \\
\hline Visualización & Juan José Rodríguez Peña \\
\hline Supervisión & $\begin{array}{l}\text { Graciela Gerarda Ayala Jiménez (principal) y Manuel López Torrijo } \\
\text { (apoyo) }\end{array}$ \\
\hline Administración de Proyectos & Juan José Rodríguez Peña \\
\hline Adquisición de fondos & NO APLICA \\
\hline
\end{tabular}

